\title{
Las fieles enemigas
}

Julián Gustems

(En un rincón de un bar)

MUJER DOS. (Entrando) Mi muñeca. ¿Hace mucho que esperas?

MUJER UNO. Apenas el tiempo de tomarme un té.

DOS. Yo detesto llegar tarde.

UNO. Es tu costumbre. Llegar tarde es un estilo.

DOS. El metro paró.

UNO: Siempre se tiene excusa. Pero no importa. El caso es que llegaste.

DOS. Te lo prometí.

UNO. Siempre cumples tus promesas. Eso sí.

DOS. No quería fallarte. Hoy menos que nunca.

UNO. Claro

DOS. Te lo debía.

UNO. ¿Me lo debías?

DOS. Te debía ser sincera contigo. Al menos en esta ocasión.

UNO. Explícate.

DOS. Antes de cruzar el charco.

UNO. Esto de ir a América ya es definitivo.
DOS. Es lo mejor que podía pasarme después de.

UNO. Después de tu fracaso.

DOS. No sé si debe llamarse fracaso a esta temporada tan irregular. Dejémoslo en irregular.

UNO. La productora no pudo cubrir ni los gastos.

DOS. No fue culpa de nosotros, los actores.

UNO. Cuando una temporada fracasa siempre es culpa de los actores. También porque la obra no valía.

DOS. No tenía ni pies ni cabeza.

UNO. La mayoría de las obras que monta esta compañía no tienen ni pies ni cabeza. Ese es el motivo de sus fracasos.

DOS. Porque nosotros ponemos toda nuestra buena voluntad en darle brillo a los textos.

UNO. Siempre.

DOS. Pero no siempre podemos conseguirlo. No somos dioses. Y el público, que siempre es riguroso, deja de darnos su aquél.

UNO. No siempre se acierta con las puestas de escena. 
DOS. En cada fracaso, nosotros los actores, nos hundimos más y más. Nos perdemos en nebulosas y al perder el aplauso del público y los plácemes de los críticos...

UNO. Y antes de no ser nadie para nadie has aceptado irte a América, como los descubridores.

DOS. Eso. A vigorizar el teatro caduco de América. A dar vida a cien personajes, a presentar las novedades de esta caduca Europa a los oriundos americanos.

UNO. Lo dices como si los americanos fuesen algo así como unos ignorantes, y no.

DOS. Y no, claro. También ellos pueden darnos motivos de cultura.

UNO. No sé si sabrán valorar tu esfuerzo.

DOS. No importa. Es trabajo ¿sabes? Y el trabajo no abunda, y menos cuando una cae por la pendiente hacia el fracaso.

UNO. Tampoco te lleves mala conciencia de tu trabajo.

DOS. Este que me ofrecen es un trabajo digno, bien pagado. Seguro.

UNO. En nuestra profesión nada es seguro.

DOS. Nada de contratos ruines, como piensas. Todavía se me tiene en estima.

UNO. Me alegra saber que no te has comprometido por cuatro perras. Los actores europeos no podemos caer tan bajo. Tenemos nuestro prestigio.

DOS. Es un punto de dignidad.
UNO. Haces bien en valorarte. Yo tampoco me daría por cuatro perras, aunque si la temporada fuese larga a lo mejor tampoco sería demasiado exigente.

DOS. Así están las cosas. Para bien o para mal así están las cosas. Pondremos a Ionesco, que siempre tiene su prestigio.

UNO. No entenderán sus textos.

DOS. Pondremos lo mejor de su teatro.

UNO. Te digo que no entenderán sus textos. Aquellas tierras son todavía amantes de los melodramas, que les va más y no para cosas que apenas si el mismo autor sabe por qué las escribió.

DOS. No creas. Antes de decidir la programación nuestro Enriquito pasó unos días estudiando la idiosincrasia de los americanos.

UNO. Para gustar de Ionesco hay que tener sus tragaderas.

A mí me encanta ese francés, ¿vale? Pero no todo el mundo sabe sacarle su aquel.

DOS. En sus dudas Enriquito ha dicho que sí. Que Ionesco.

UNO. Eso lo decidió sin consultarnos.

DOS. No tenía por qué. Eso de las programaciones ha sido siempre cosa suya. Suya y de los patrocinadores.

UNO. Debió sentirse muy solo allá en las Américas, sin que le diésemos nuestro calor. 
DOS. Tendría otros calores, no creas. Que Enriquito ya sabes que en esto de los calores...

UNO. Nos hemos perdido el placer de su presencia. Estos días sin nosotras le habrán parecido eternos.

DOS. Tampoco han sido tantos días. Aquí me han pasado las horas sin sentir.

UNO. También para él le habrán parecido un soplo. Las horas del día son igual de largas para todo el mundo.

DOS. Para mí, en la preparación de mis cositas, los días han pasado sin sentir. Me llevo una montaña de libros, programas y ropita.

UNO. Yo me di el gustazo de pasearme cerca del mar, hundiendo los pies en la mojada arena. Pensando en ti, en Enriquito y en mis cosas. Los dedos sobre la arena dan un placer que no puede explicarse. ¡Hacía tantos años que no experimentaba tanto placer!

DOS. Y ¿a qué vienen ahora tus desahogos?

UNO. Porque ahora estaré sola. Sola con mis buenos recuerdos, claro.

DOS. Yo voy a olvidarme de las noches sin éxito. Voy a encontrarme con otros mundos, otras ideas y, posiblemente con otros amores.

UNO. Yo no quise unirme a esta aventura.

DOS Pues pensaron en ti. Querían proponerte para un papel de característica.

UNO. ¿Si? ¿Quién lo propouso?

DOS. El propio Enriquito.
UNO: Claro. Quería tenernos a las dos a su alcance.

DOS. Yo me opuse.

UNO. ¿Te opusiste? ¿Sabiendo que no tenía trabajo, te opusiste?

DOS. Pensé que te ofenderían con un contrato de característica, a ti que eras tan joven. Por esto me opuse, porque soy tu amiga y no deseo para ti ningún mal.

Aunque a ti no te lo parezca me caes muy bien.

UNO. Aunque entre tú y yo exista el problema de Enriquito.

DOS. Enriquito no es un problema. Al menos para mí.

UNO. Enriquito es un problema para las dos.

DOS A Enriquito le tengo cogido por el corazón.

UNO. !El corazón ¡No seas cursi, a Enriquito le tenemos cogido por nuestras piernas!

DOS. No seas vulgar.

UNO. Y tú no seas ingenua. Aunque te creas una niña virgen ni eres niña ni eres virgen.

DOS. No me interesan estas cosas de la niñez. Perdí la virginidad cuando dejé de ser niña.

UNO. También la perdí yo. Y no es cosa de lamentarse, porque las mujeres estamos para esto: para ir perdiéndolo todo. Pero si pierdo a Enriquito pierdo muy poco porque ya ahora lo estoy compartiendo contigo. 
Pero no me importa demasiado ¿sabes? Porque no han de faltarme otros Enriquitos.

DOS. Tú sabes que me entiendo con él.

UNO Y buen provecho te haga. Si hasta ahora lo hemos compartido como buenas amigas y mejores patriotas, de ahora en adelante lo habremos de compartir con las espléndidas americanas que babosearán con él. Pero tú, que seguirás por las mismas calles $\mathrm{y}$ los mismos éxitos, tendrás que ganarte su voluntad y su cariño como si empezaras de nuevo. Será una difícil batalla, sospecho.

DOS. Volveré a conquistarlo. Facultades no me faltan.

Las armas de las mujeres son siempre las mismas. Saber manejarlas mejor o por son cosas de las circunstancias. Y en este terreno sé manejarme bien.

UNO. No te valdrá que no vaya a las Américas para que te salgan nuevos problemas. Recuerda que Enriquito no es tu esclavo y que cualquier piedrecita que se cruce en su camino puede hacer peligrar tu amor por él.

DOS. No le perderé de vista ni un momento.
UNO. Piensa en mí cuando interpretes a Ionesco. ¿No vale lo absurdo de su teatro para compararlo con lo absurdo de nuestra vida?

DOS. Para mí de ahora en adelante solo me salvarán Ionesco y Enriquito.

UNO. Pero tú sabes que esta tarde la pasé con él. Para despedirme. Porque me dolía perderle sin conseguir de él un último placer.

DOS. Entonces ¿esta tarde?

UNO. Sabrás perdonármelo, supongo. Porque es la última de las tardes y de ahora en adelante ya no habrá otras.

DOS. No digo que no me duele.

UNO. He tenido que descargar mi conciencia. Espero que lo comprendas.

DOS. No te lo perdono. Pero lo comprendo porque yo habría hecho otro tanto.

UNO. Así pues podemos despedirnos como buenas amigas. Deseándonos lo mejor.

DOS. Podemos tomarnos el té. Si te apetece.

UNO. Me apetece. Yo lo tomaré frío, con un poco de leche de vaca. Por eso de los cuernos. 